\title{
Attenuation relationships of peak ground motions in the Jazan Region
}

\author{
Ali K. Abdelfattah ${ }^{1,2} \cdot$ Abdullah Al-amri $^{1} \cdot$ Kamal Abdelrahman $^{1,2} \cdot$ Muhamed Fnais $^{1} \cdot$ Saleh Qaysi ${ }^{1}$
}

Received: 2 September 2020 / Accepted: 30 December 2020 / Published online: 21 January 2021

(C) The Author(s) 2021

\begin{abstract}
In this study, attenuation relationships are proposed to more accurately predict ground motions in the southernmost part of the Arabian Shield in the Jazan Region of Saudi Arabia. A data set composed of 72 earthquakes, with normal to strike-slip focal mechanisms over a local magnitude range of 2.0-5.1 and a distance range of 5-200 km, was used to investigate the predictive attenuation relationship of the peak ground motion as a function of the hypocentral distance and local magnitude. To obtain the space parameters of the empirical relationships, non-linear regression was performed over a hypocentral distance range of 4$200 \mathrm{~km}$. The means of 638 peak ground acceleration (PGA) and peak ground velocity (PGV) values calculated from the records of the horizontal components were used to derive the predictive relationships of the earthquake ground motions. The relationships accounted for the site-correlation coefficient but not for the earthquake source implications. The derived predictive attenuation relationships for PGV and PGA are

$\log _{10}(P G V)=-1.05+0.65 \cdot M_{L}-0.66 \cdot \log _{10}(r)-0.04 \cdot r$
$\log _{10}(P G A)=-1.36+0.85 \cdot M_{L}-0.85 \cdot \log _{10}(r)-0.005 \cdot r$

respectively. These new relationships were compared to the grand-motion prediction equation published for western Saudi Arabia and indicate good agreement with the only data set of observed ground motions available for an $M_{L} 4.9$ earthquake that occurred in 2014 in southwestern Saudi Arabia, implying that the developed relationship can be used to generate earthquake shaking maps within a few minutes of the event based on prior information on magnitudes and hypocentral distances taking into considerations the local site characteristics.
\end{abstract}

Keywords Attenuation $\cdot$ Earthquake ground motion $\cdot$ PGA $\cdot$ Arabian shield $\cdot$ Saudi Arabia

\section{Introduction}

Earthquakes that occur offshore and along the eastern shore of the Red Sea are caused by tectonic processes acting in the vicinity of the Arabian Shield. Several of these seismic source

This article is part of the Topical Collection on Advances of Geophysical and Geological Prospection for Natural Resources in Egypt and the Middle East

Ali K. Abdelfattah

ali_kamel@yahoo.com

1 Department of Geology \& Geophysics, King Saud University, Riyadh 11451, Kingdom of Saudi Arabia

2 Department of Seismology, National Research Institute of Astronomy and Geophysics, Cairo, Egypt zones are potential sources of seismic hazard for metropolitan areas. Because of the geodynamic processes in the region, the territory of the Arabian Plate is being dragged northward in intensive movements, resulting in complex local tectonic settings and causing this territory to trigger moderate seismicity and form complicated geological structures in many areas (Abdelfattah et al. 2017, 2020). This seismotectonic setting strongly indicates that Saudi Arabia has experienced considerable earthquakes in the past and will experience them in the future, in particular along the coastline both onshore and offshore the Red Sea. Historical documents indicate that an earthquake of magnitude 7 occurred in 1068 in the northwestern Arabian Peninsula (Ambraseys et al. 2005). During the last century, earthquakes of $M w 5.1$ in 2004 (Aldamegh et al. 2009), Mw 5.4 in 2009 (International Seismological Centre), $M w 3.9$ in 2009 (Aldamegh et al. 2010), Mw 4.6 in 2014 
(Abdelfattah et al. 2017), and $M w 4.0$ in 2017 (Abdelfattah et al. 2020) have occurred.

The seismic hazard assessment over Saudi Arabia Peninsula is limited and focuses mainly on the probabilistic seismic hazard analysis (PSHA). The PSHA was quantified by Al-Amri (2013), and Zahran et al. $(2015,2016)$ using GMPEs of different areas outside Saudi Arabia. Moreover, the deterministic seismic hazard (DSH) was analyzed in some local areas located along the eastern coastline of the Red Sea (Almadani et al. 2015). However, the DSH does not well cover the whole area of the western Saudi Arabia peninsula. Owing to no ground motion distance attenuation relationships developed specifically for Saudi Arabia, several different ground motion prediction equations (GMPEs) were used in regions where no strong ground motion records were available (e.g., Thenhaus et al. 1989; Fukushima and Tanaka 1990; Sadigh et al. 1997; Skarlatoudis et al. 2004; Pankow and Pechmann 2004; Ambraseys et al. 2005; Atkinson and Boore 2006; Zhao et al. 2006; Akkar et al. 2014). Recently, a regional GMPE was established by Kiuchi et al. (2019) for western Saudi Arabia. Abdelwahed et al. (2020) used predictive attenuation relationships from different regions to identify appropriate relationships capable of predicting ground motions in the region. Besides, Abdelfattah et al. (2020) developed an application based on an empirical Green's function summation technique to simulate seismic ground motion records in the Jazan Region of Saudi Arabia using the waveform data and source parameters derived from the spectral amplitudes of an $M w 3.4$ event. The estimated peak ground acceleration (PGA) values are consistent with the GMPEs derived for California, Japan, and western Saudi Arabia. The results appear to be capable of predicting ground motions for future earthquakes; therefore, GMPEs in the region can be optimized by incorporating the effects of local geological conditions.

The southernmost part of the Arabian Shield is located near a triple junction that connects the axial rift in the southern Red Sea, the rifting system in the Afar Region, and the rifting process in the Gulf of Aden. The deformation in this region is attributed to the relative movement between the Arabian and African plates and the active rifting processes in the region. Even though this region is not considered to have a high rate or size of seismicity, earthquake hazard prevention and mitigation need to be seriously considered; this region is of high interest because the government plans to erect some dams in the area. Also, this region is home to one of the major cities in the territory of Saudi Arabia where most of the mega projects exploit green technologies to produce electricity. Together with the population, this has motivated many researchers to assess the earthquake hazards and the related earthquake engineering functions in this region. For more precise seismic hazard assessments, a local predictive equation of earthquake ground motions needs to consider the local characteristics of the source effects, receiver-to-path effects, and local geological conditions in a specific region. Accordingly, it is crucial to define the attenuation relationships to more accurately predict GMPEs, specifically for urban development plans and earthquake hazard assessments in specific regions, which will be essential to assess earthquake hazards for fast-economic growth regions such as the Jazan Region. The Saudi Geological Survey records provide an opportunity to access records at sites that will provide an important reference to establish a regional GMPE.

\section{Data}

Waveform data were collected at broadband seismic stations, shown in Fig. 1, that belong to the seismographic network operated by the Saudi Geological Survey. This network consists of two types of velocity seismometers, STS-2 and Trillium 40, which have flat responses approximately ranging from 0.008 to $50 \mathrm{~Hz}$ and from 0.025 to $50 \mathrm{~Hz}$, respectively.

Figure 1 shows the geographical locations of the seismic stations and the distribution of the earthquake epicenters used in the present analysis. A plot showing the magnitude as a function of the distance is shown in Fig. 2. Note that the local magnitude is the only magnitude estimate available for most events, except for a few earthquakes. Following the method of Gupta et al. (2017), the signal-to-noise ratio between the $\mathrm{S}$ waves and the noise window prior to the $\mathrm{P}$ wave arrivals was examined to select the appropriate records for this study. The instrumental response was deconvolved from the selected seismograms, and then the records were differentiated into acceleration records. A total of 769 records with a good signal-to-noise ratio, related to 99 earthquakes and 150 stations, were selected to update the GMPEs for the region over the magnitude range from 4.1 to 6.9 . Figure 3 shows example velocity records of an $M_{L} 4.9$ earthquake that occurred on August 03, 2014, at 20:21:11.26 UTC. Figure 4 shows the distribution of the focal mechanism solutions that were available for a few events in the region, which indicate normal to strike-slip focal mechanisms. The focal depths of the earthquakes were generally shallower than $10 \mathrm{~km}$. An extensional tectonic regime is associated with the earthquakes that occurred along the axial rift of the Red Sea, while a shear tectonic regime is associated with the earthquakes that occurred along the reactivation of the inherited conjugate fault system in the region (Abdelfattah et al. 2020).

\section{Method}

The decay of ground motion amplitudes can be expressed as an exponential function that represents the effects of the geometric spreading and anisotropic attenuation coefficients in the form

$A \sim r^{n} \exp ^{\gamma r}$, 
Fig. 1 Map showing the tectonic plate boundaries near the showing the spatial distribution of the epicenters in the period from 2002 to 2017 in the epicentral area and its vicinities (light brown polygons indicate the wide distribution of ancient Cenozoic basaltic fields called Harrats) epicentral area with an inset

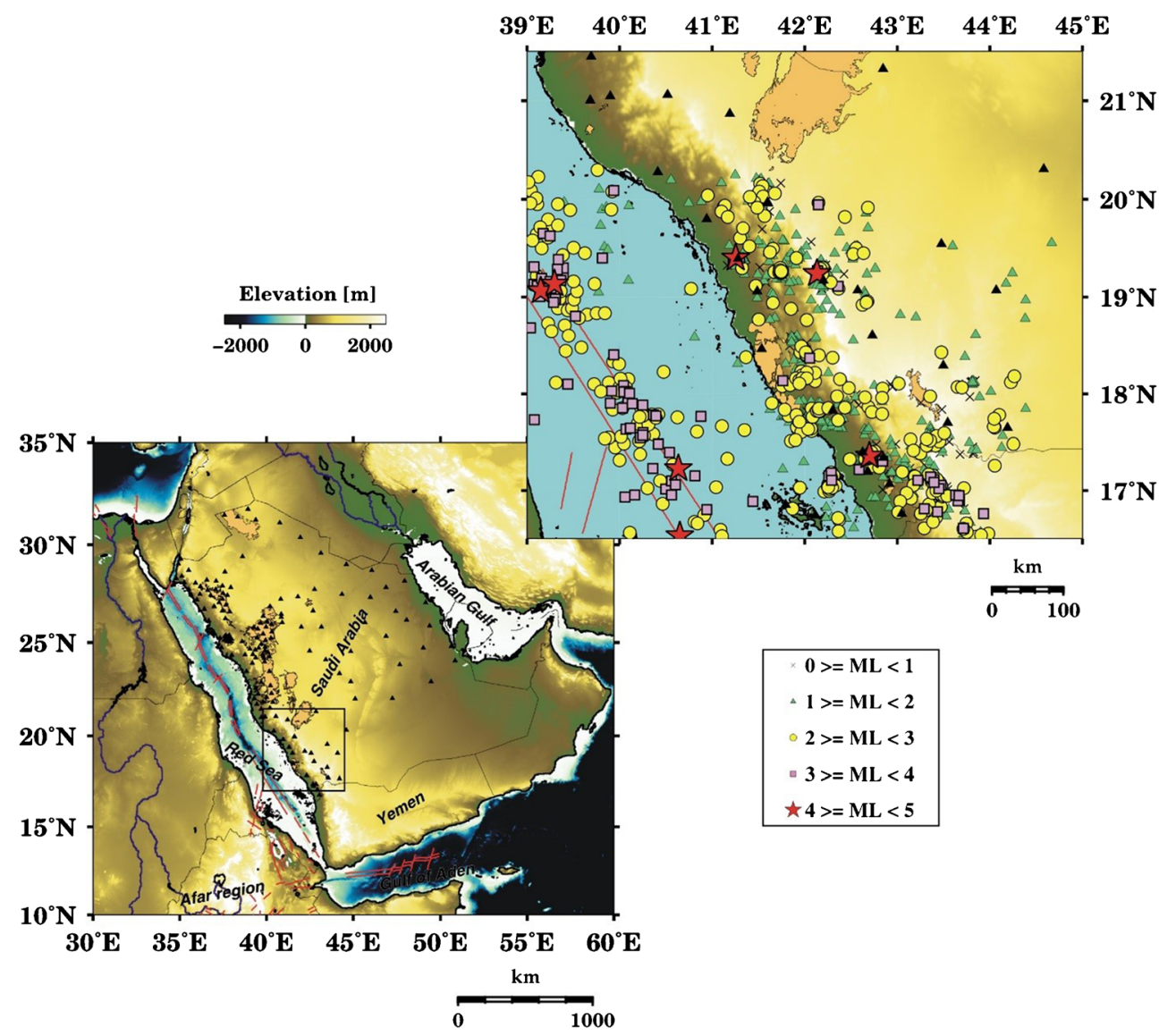

where $A$ is the amplitude of the ground motion, $r$ is the hypocenter or epicenter distance, $n$ is the geometrical spreading coefficient, and $\gamma$ is the anelastic attenuation coefficient. Taking the logarithm of both sides of Eq. (1), we find

$\log _{10}(A)=c^{-}-\gamma r-n \log _{10}(r)$,

where $c$ is a constant. The geometric spreading coefficient is

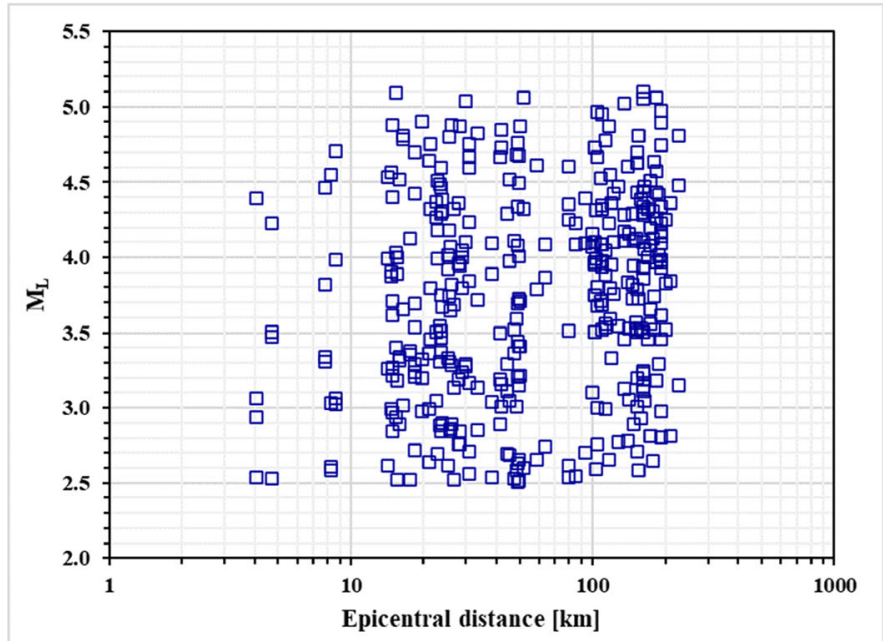

Fig. 2 Distribution of earthquake magnitudes as a function of the epicentral distance (left) and histogram of the records and corresponding magnitude classes for the data set used in the present analysis (right). The equal to 1 for the propagation properties that affect the transmission of seismic waves along the source-to-receiver paths. Taking into consideration the variation in the ground motion amplitudes with magnitude, the attenuation relationship to predict the earthquake ground motion can be written as

$\log _{10}(A)=a+b \cdot M_{L}-c \cdot \log _{10}(r)-d \cdot r$,

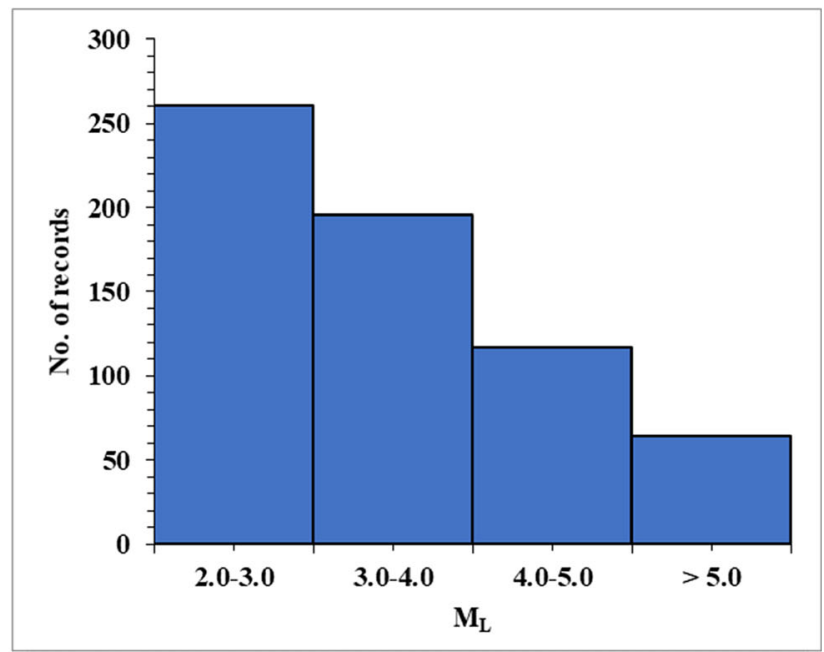

data set comprises 72 earthquakes having a local magnitude range from 2.0 to 5.1 recorded by seismic stations distributed over a distance range of $5-200 \mathrm{~km}$ 
Fig. 3 Velocity seismograms of an event recorded at different stations for an earthquake that occurred on August 08, 2014, at 20:21:11.26 UTC (red lines show the picking marks for the $\mathrm{P}$ and $\mathrm{S}$ wave arrival times)

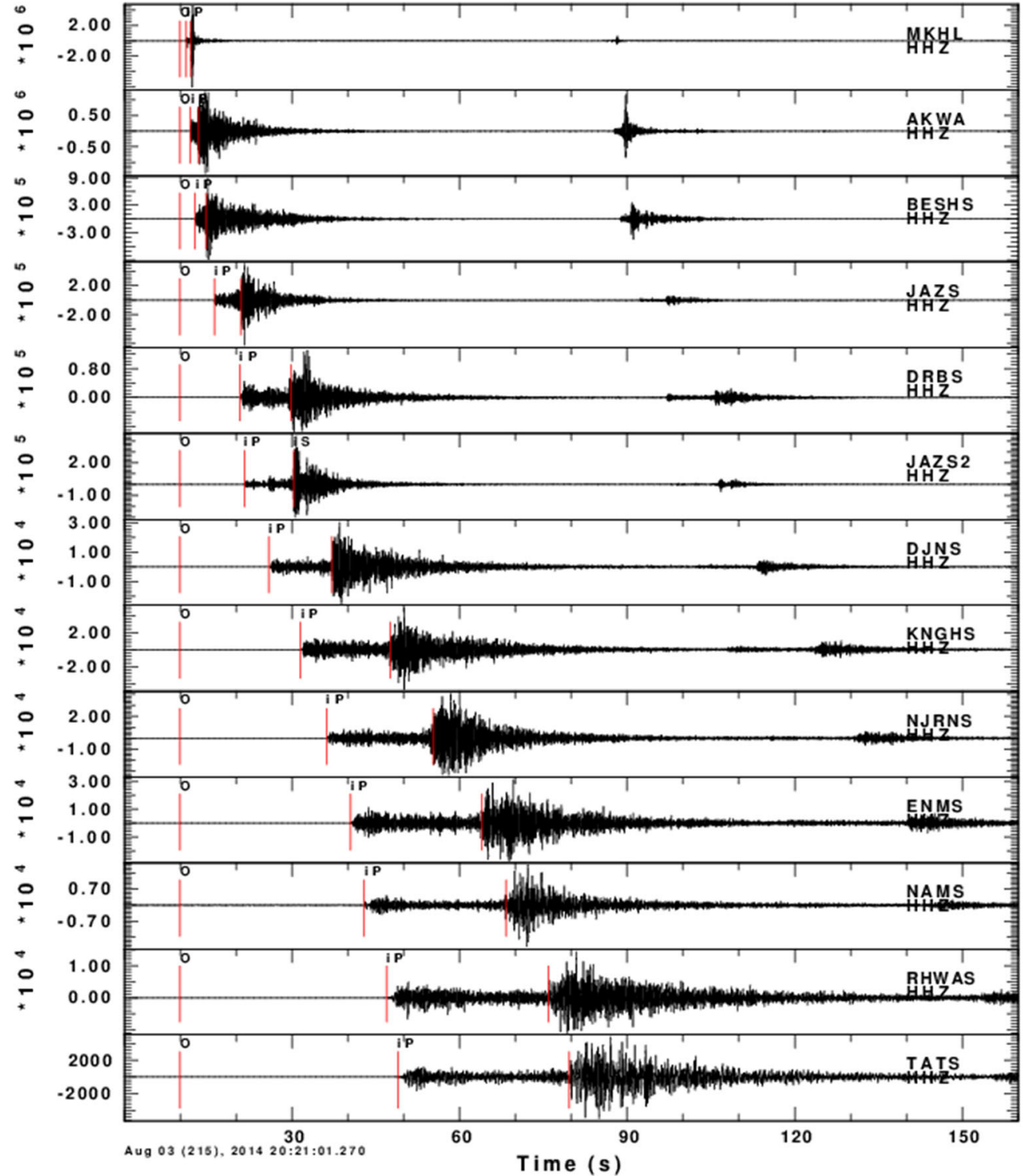

where $A$ is either PGA or the peak ground velocity (PGV) and $M_{L}$ is the local magnitude. To solve Eq. (3), the scaling coefficients, $a, b, c$, and $d$, can be determined using regression analysis. Accordingly, Eq. (3) can be rewritten in matrix form as

$$
\left|\begin{array}{c}
\log _{10}\left(A_{11}\right) \\
\log _{10}\left(A_{12}\right) \\
\vdots \\
\log _{10}\left(A_{m n}\right) \\
\log _{10}\left(A_{21}\right) \\
\log _{10}\left(A_{22}\right) \\
\vdots \\
\log _{10}\left(A_{m n}\right) \\
\vdots \\
\vdots
\end{array}\right|=\left|\begin{array}{cccc}
1 & M_{L_{1}} & \log _{10}\left(r_{11}\right) & r_{11} \\
1 & M_{L_{1}} & \log _{10}\left(r_{12}\right) & r_{12} \\
\vdots & \vdots & \vdots & \vdots \\
1 & M_{L_{m}} & \log _{10}\left(r_{m n}\right) & r_{m n} \\
1 & M_{L_{2}} & \log _{10}\left(r_{21}\right) & r_{21} \\
1 & M_{L_{2}} & \log _{10}\left(r_{22}\right) & r_{22} \\
1 & \vdots & \vdots & \vdots \\
1 & M_{L_{m}} & \log _{10}\left(r_{m n}\right) & r_{m n} \\
\vdots & \vdots & \vdots & \vdots \\
\vdots & \vdots & \vdots & \vdots
\end{array}\right| .
$$

The two-step approach has been proposed by Joyner and Boore (1981) to find space model parameters that can be used to model predictive relationships of the earthquake ground motions. The approach aims to reduce the effect of the distance-magnitude correlation on observed strong motion data sets. In addition, Joyner and Boore (1993) revealed that the methods of the stagewise regression yield comparable results with that obtained from a single-step analysis using the maximum likelihood technique. However, the methods based on the stagewise regression provide results with less accuracy than a single-step maximum likelihood analysis (Draper and Smith 1981); accordingly, the method based on the singular value decomposition of (Lanczos 1961) was used to solve the least-squares problem in this analysis. The applied method controls the stability to obtain the optimum estimates and uncertainties in the final solution (Press et al. 1992). Furthermore, the present analysis overcomes and quantifies the influence of the distance-magnitude correlation on the observed data set. 
Fig. 4 Distribution of earthquake ground motions (open blue squares) and the corresponding predictive attenuation relations (solid red lines) for the mean values of PGV (a) and PGA (b) recorded by the horizontal components of the seismic stations listed in Table 1
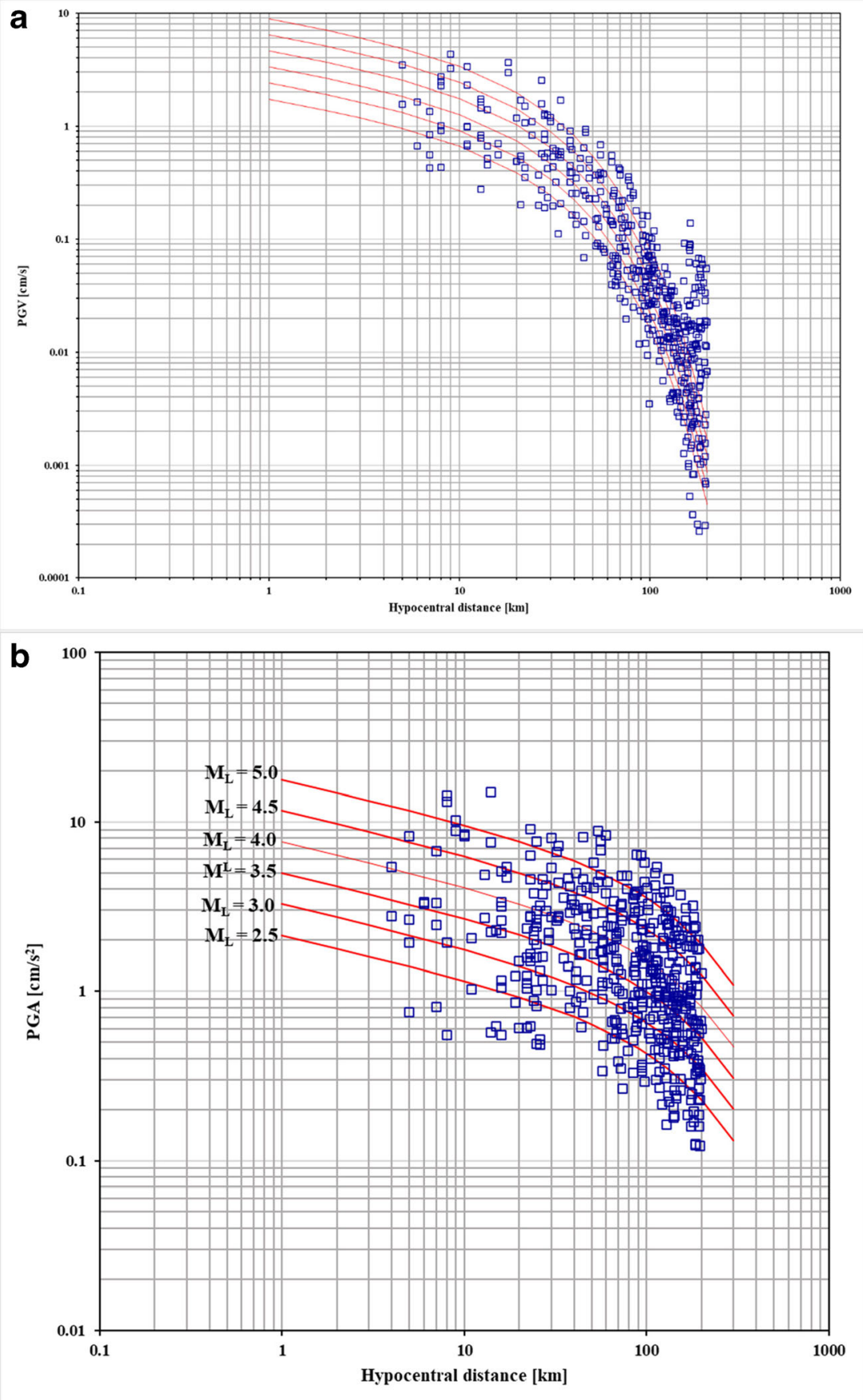

The site-effect term can be estimated using the residual between the observed and predicted PGA values:

$r e s_{i}=\ln \left(\frac{A_{i}}{A c_{i}}\right)$,

where $A c_{i}$ indicates the predicted PGA or PGV values. Taking the average of the residual at each station, a coefficient representing the average site-effect term can be computed using the equation of Wu et al. (2001):

$$
S=\exp \left(\frac{1}{n} \sum_{i=1}^{N} \operatorname{res}_{i}\right)
$$

\section{Results and discussion}

It is worth stressing that seismograms recorded at good sites are an important reference when establishing the predictive 
Table 1 List of seismic stations and their parameters (site correction factors, instrumental types, and site classes) used in this study

\begin{tabular}{llllll}
\hline Code & Lat $\left(^{\circ}\right)$ & Long $\left(^{\circ}\right)$ & Site corr. & Instrument & Site classes \\
\hline MKHL & 17.3650 & 42.6810 & 2.34 & STS-2 & B \\
AKWA & 17.2610 & 42.6990 & 2.12 & Trillium 120 & B \\
BESHS & 17.3651 & 42.8395 & 1.89 & Trillium 120 & B \\
JAZS & 17.0684 & 42.9174 & 0.98 & Trillium 120 & A \\
DRBS & 17.8281 & 42.3010 & 1.08 & Trillium 120 & A \\
JAZS2 & 16.7587 & 43.0486 & 1.10 & Trillium 120 & A \\
FRSS & 16.7383 & 42.1152 & 1.34 & Trillium 120 & C \\
DJNS & 17.7014 & 43.5449 & 1.06 & STS-2 & A \\
FRSS2 & 16.8520 & 41.7940 & 1.47 & Trillium 120 & C \\
KNGHS & 17.3650 & 43.4962 & 1.13 & Trillium 120 & A \\
NJRNS & 17.6521 & 44.1923 & 1.08 & Trillium 120 & A \\
AMGES & 18.4649 & 41.5363 & 1.11 & Trillium 120 & A \\
ENMS & 19.0707 & 42.5717 & 0.97 & Trillium 120 & A \\
NAMS & 19.1702 & 42.2021 & 1.68 & STS-2 & A \\
RHWAS & 19.0708 & 44.0707 & 1.17 & Trillium 120 & A \\
TATS & 19.5416 & 43.4773 & 1.14 & Trillium 120 & A \\
BAHS & 19.9699 & 41.5993 & 1.77 & Trillium 120 & B \\
\hline
\end{tabular}

GMPE in a region. Using the data set composed of 638 records from 72 earthquakes over the local magnitude range of 2.0-5.1 and the hypocentral distance range of 4-200 km, the empirical predictive relationships of the earthquake ground motions were defined in the Jazan Region. Simultaneous non-linear regression was applied to solve Eq. (4), and the empirical predictive relationships were defined for the PGA and PGV values based on the mean values estimated by taking the average values recorded for the two horizontal components. The results are summarized in the following equations.

$\log _{10}(P G A)=-1.36+0.85 \cdot M_{L}-0.85 \cdot \log _{10}(r)-0.005 \cdot r$

$\log _{10}(P G V)=-1.05+0.65 \cdot M_{L}-0.66 \cdot \log _{10}(r)-0.04 \cdot r$

The influence of the focal mechanisms on the predictive attenuation relationships of the ground motion has been mentioned and discussed in many studies (e.g., Campbell 1984, 1997; Sadigh et al. 1997; Boore et al. 1997; Anooshehpoor and Brune 2002; Kiuchi et al. 2019). These studies revealed that PGAs released from trust source mechanisms tend to be higher than other source mechanisms. Unfortunately, the number of fault plane solutions in this study, shown in Fig. 1 , was insufficient to explore the effect of the source mechanisms. The station locations are listed in Table 1 with their corresponding site classes and site correction factors.

The geological setting of the study area, as a part of the Arabian Shield, is primarily composed of exposed Precambrian basement, ranging in age from $1000 \mathrm{Myr}$ to 545 Myr, having formed from thick sequences of late Oligocene to Holocene volcanic rocks developed with the spreading of the Red Sea (Camp and Roobol 1989). Figure 5 shows the effect of the coefficient $d$ in Eq. (3), which represents the effect of the anelastic attenuation in western Saudi Arabia, indicating low anelastic attenuation in this region, which is in good agreement with the stable Precambrian geology of the Arabian Shield. The attenuation characteristics were estimated using the following form:

$\frac{1}{Q}=-\frac{\beta d}{\pi f}$,

where $\beta$ is the shear wave velocity in the study region set to $3.5 \mathrm{~km} / \mathrm{s}$ as taken from Rodgers et al. (1999) and $f$ is the frequency in Hz. It is obvious from Fig. 7 that the results are

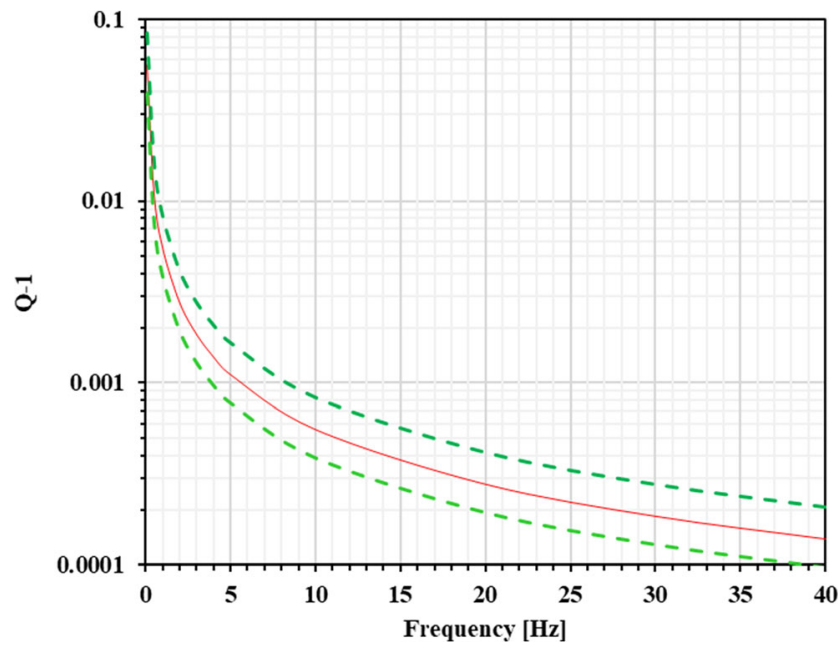

Fig. 5 Frequency-dependent attenuation frequency in the studied region, where the relationship represents the effect of the calculated anelastic attenuation using the value of the coefficient $d$ represented in Eq. (3). Dashed lines represent the 16th and 84th percentile limits of the standard deviation curves 
Fig. 6 PGA attenuation curves derived in this study (solid blue line) and in that of Kiuchi et al. (2019) for strike-slip focal mechanisms (solid red line), with the strong ground motion (open blue squares) of an $M_{L} 4.9$ earthquake that occurred in the Jizan Region in 2014 clearly showing the effect of the local site conditions at two stations located at hypocentral distances of approximately $200 \mathrm{~km}$ (encircled in red). Dashed lines represent the 16th and 84th percentile limits of the standard deviation curves for the attenuation relationship derived in this study

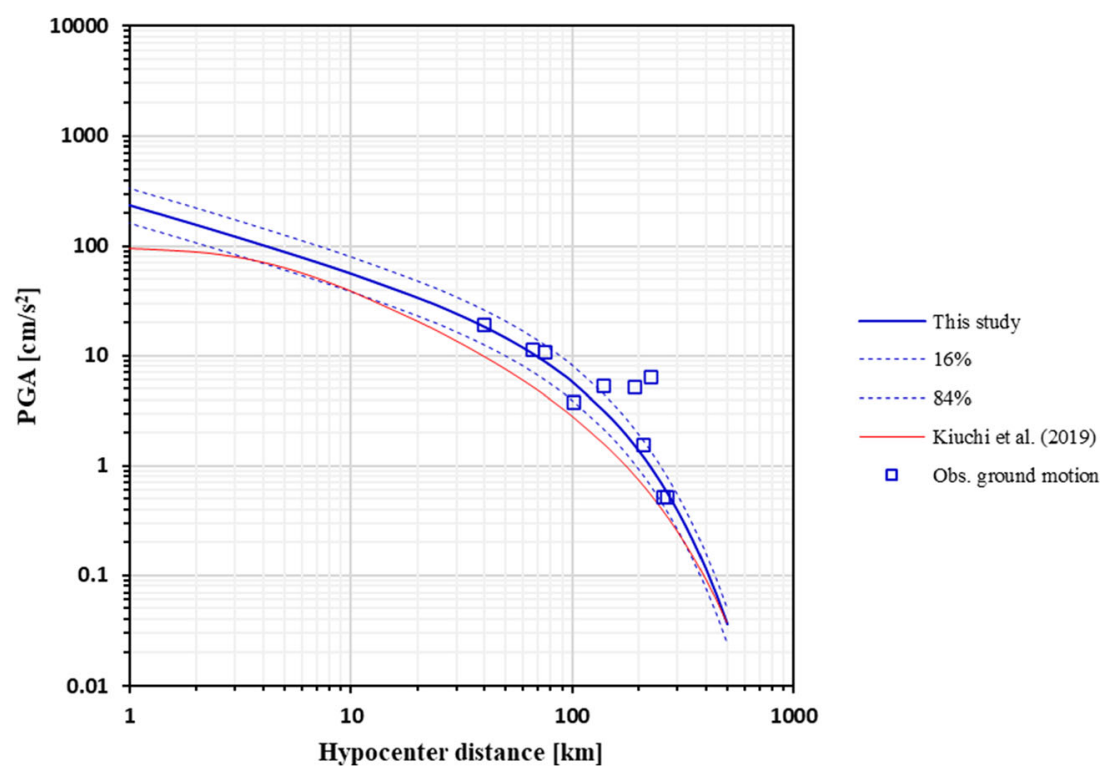

comparable, to some degree, to the low attenuation characteristics that were determined by Pasyanos et al. (2009) and Abdel-Fattah et al. (2014) in the Arabian Shield. The frequency-dependent attenuation frequency generally indicates an inversely proportional relationship.

On January 23, 2014, a moderate-sized earthquake of $M_{L}$ 4.9 occurred in the southernmost part of the Arabian Shield in the Jizan Region. This earthquake had a focal depth of $10 \mathrm{~km}$ and exhibited a dextral strike-slip focal mechanism over the ENE fault trend, implying the reactivation of a vertical fault in the Precambrian basement. A maximum modified Mercalli intensity of V-VI was widely felt in the epicentral area, as reported by El-Hadidy (2015). Fortunately, this event was recorded by a total of 10 strong ground motion stations, providing unique data that were previously unavailable. Figure 6 shows a comparison of the derived PGA attenuation relationships (this study and that of Kiuchi et al. (2019)) with the observed values scaled to $M_{L} 4.9$; these are plotted with the 16 th and 84th percentile limits of the standard deviation curves for the attenuation relationship derived in this study. The derived relationships account for the site correction coefficient, which was estimated based on the residuals between the observed and predicted peak ground motion values. However, further studies will be required to calibrate the source terms when a large number of focal mechanism solutions are available. It is noteworthy that the relationship Kiuchi et al. (2019) indicated lower predictive ground acceleration than the currently derived equation. There are some
Fig. 7 A comparison between several GMPEs from different areas and the GMPE derived in the present study, revealing that the present GMPE is capable of predicting ground motions from future large earthquakes. The GMPE models are abbreviated as THEN for the Eastern United States and the Mississippi Valley (Thenhaus et al. 1989), FT for Japan (Fukushima and Tanaka 1990), SAD for California (Sadigh et al. 1997), SKA for Greece (Skarlatoudis et al. 2004), AM for Europe and the Middle East (Ambraseys et al. 2005), AB for Europe and the Middle East (Akkar and Bommer 2010), and KIK for western Saudi Arabia (Kiuchi et al. 2019)

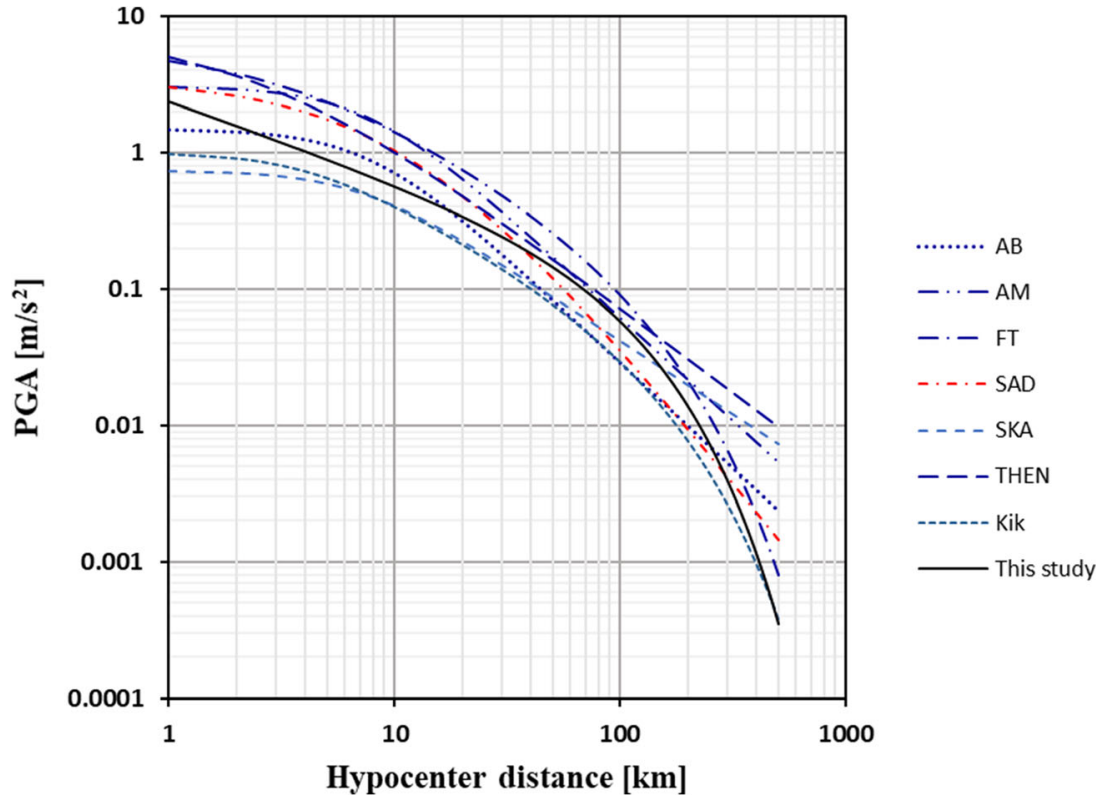


factors that may probably cause the difference between two predictive relations due to the multiple different steps followed in the processing and regression analysis, the different data sets used in the two studies, and the influence of source mechanisms that were not accounted for in this study. However, our predictive relationship shows good agreement with the observed PGA values of the 2014 earthquake, as opposed to that derived by Kiuchi et al. (2019), which means that our relationship is capable of predicting the ground motions of future earthquakes in this region.

The relationship that was developed in this study can be used not only to predict the ground accelerations from future earthquakes but also to generate earthquake shaking maps within a few minutes of the event based on routine estimates for magnitudes and hypocentral distances by incorporating the effects of local geological conditions. Figure 7 shows a comparison between the derived GPME in this study and seven different GMPE models derived in the Eastern United States and the Mississippi Valley (Thenhaus et al. 1989), Japan (Fukushima and Tanaka 1990), California (Sadigh et al. 1997), Greece (Skarlatoudis et al. 2004), Europe and the Middle East (Ambraseys et al. 2005), Europe and the Middle East (Akkar and Bommer 2010), and western Saudi Arabia (Kiuchi et al. 2019). The seven models are consistent with our model for distances ranging from 3 to $300 \mathrm{~km}$, revealing that our model is capable of predicting ground motions from future large earthquakes.

\section{Conclusions}

Predictive attenuation relationships for earthquake ground motions are of great importance when assessing seismic hazards in a specific region. These relationships are used by engineers to overcome design problems; an overestimation of ground motions may lead to additional costs in structural designs, while underestimations result in disasters in the event of large ground motions. The predictive attenuation relationships account for the uncertainty in PGA and PGV as a function of the earthquake size, source-to-site paths, and local geological conditions.

Based on our analysis of the means of 638 PGA and PGV values calculated from the horizontal component records, attenuation relationships were derived to predict the earthquake ground motions in the southernmost part of the Arabian Shield for earthquakes with magnitudes ranging from 2.0 to 5.1 and over hypocentral distances ranging from 4 to $200 \mathrm{~km}$. The predictive attenuation relationships obtained in this study revealed good agreement with the published GMPE for western Saudi Arabia. Moreover, the predictive attenuation relationship of the PGA values compared well with the observed ground motions recorded from the 2014 earthquake. The attenuation relationships obtained in this study can therefore be used to assess the probabilistic seismic hazards and earthquake shaking maps in the region within a few minutes of the earthquake occurrences based on the prior information on magnitudes and hypocentral distances by incorporating local site responses.

Funding This research was funded by the National Plan for Science, Technology and Innovation (MAARIFAH), King Abdulaziz City for Science and Technology, Kingdom of Saudi Arabia, Award Number (14-SPA576-02).

Open Access This article is licensed under a Creative Commons Attribution 4.0 International License, which permits use, sharing, adaptation, distribution and reproduction in any medium or format, as long as you give appropriate credit to the original author(s) and the source, provide a link to the Creative Commons licence, and indicate if changes were made. The images or other third party material in this article are included in the article's Creative Commons licence, unless indicated otherwise in a credit line to the material. If material is not included in the article's Creative Commons licence and your intended use is not permitted by statutory regulation or exceeds the permitted use, you will need to obtain permission directly from the copyright holder. To view a copy of this licence, visit http://creativecommons.org/licenses/by/4.0/.

\section{References}

Abdelfattah AK, Al-Amri A, Abdel el-aal AK, Zaidi FK, Fnais M, Almadani S, Al-Arifi N (2017) The 23 January 2014 Jizan earthquake and its tectonic implications in southwestern Saudi Arabia. Tectonophysics 712-713:494-502

Abdelfattah AK, Al-amri A, Soliman MS, Zaidi FK, Qaysi S, Fnais M, Almadani M, Al-Arifi N (2020) An analysis of a moderate earthquake, eastern flank of the Red Sea, Saudi Arabia. Earth Planets Space 72(34):1-17. https://doi.org/10.1186/s40623-020-01159-5

Abdel-Fattah AK, Al-Amri AM, Fnais MS, Abdelrahman K (2014) Estimation of source parameters and attenuation using digital waveforms of Al-Ays 2009 earthquake, Saudi Arabia. Arab J Geosci 7: 3325-3337

Abdelwahed MF, El-Masry NN, Qaddah A, Moufti MR, Alqahtani F (2020) Spatial distribution of the empirical peak ground motion in Western Saudi Arabia and its implication on Al-Madinah City. Arab J Geosci 13:22-32

Akkar S, Bommer JJ (2010) Empirical equations for the prediction of PGA, PGV, and spectral accelerations in Europe, the Mediterranean region and the Middle East. Seismol Res Lett 81: 195-206

Akkar S, Sandıkkaya MA, Bommer JJ (2014) Empirical ground-motion models for point- and extended-source crustal earthquake scenarios in Europe and the Middle East. Bull Earthquake Eng 12:359-387

Aldamegh K, Abou Elenean K, Hussein H, Rodgers A (2009) Source mechanisms of the June 2004 Tabuk earthquake sequence, Eastern Red Sea margin, Kingdom of Saudi Arabia. J Seismol 13:561-576

Aldamegh K, Hussein H, Al-Arifi N, Moustafa S, Moustafa M (2010) Focal mechanism of Badr earthquake, Saudi Arabia of August 27, 2009. Arab J Geosci 5(4):599-606

Al-Amri AM (2013) Seismotectonics and seismogenic source zones of the Arabian Platform. In: Al Hosani K, Roure F, Ellison R, Lokier S (eds) Lithosphere Dynamics and Sedimentary Basins: The Arabian Plate and Analogues. Frontiers in Earth Sciences. Springer, Berlin, Heidelberg. https://doi.org/10.1007/978-3-642-30609-9_15 
Almadani S, Al-Amri A, Fnais M, Abdelrahman K, Ibrahim E, Abdelmoneim E (2015) Seismic hazard assessment for Yanbu metropolitan area, western Saudi Arabia. Arab J Geosci 8:9945-9958

Ambraseys NN, Douglas J, Sarma K, Smit PM (2005) Equations for the estimation of strong ground motions from shallow crustal earthquakes using data from Europe and the Middle East: Horizontal Peak Ground Acceleration and Spectral Acceleration. Bull Earthq Eng 3:1-53

Anooshehpoor R, Brune JN (2002) Precarious rock evidence for low ground accelerations associated with normal faults and extensional strike-slip faults, in Proc. of the 2002 AGU Fall Meeting, 6-10 December, San Francisco, S71B-1078

Atkinson GM, Boore DM (2006) Earthquake ground-motion prediction equations for eastern North America. Bull Seismol Soc Am 96: 2181-2205

Boore DM, Joyner WB, Fumal TE (1997) Equations for estimating horizontal response spectra and peak acceleration from western North American earthquakes: a summary of recent work. Seismol Res Lett 68:128-153

Camp VE, Roobol MJ (1989) The Arabian continental alkali basalt province: part I, evolution of Harrat Rahat, Kingdom of Saudi Arabia. Geol Soc Am Bull 101:71-95

Campbell KW (1984)Near-source attenuation of strong ground motion for moderate to large earthquakes: an update and suggested application to the Wasatch fault zone in north-central Utah, in Proc. of Workshop on Evaluation of Regional and Urban Earthquake Hazards and Risks in Utah, Salt Lake City, U.S. Geol. Surv. Open-File Rept 84-763:483-499

Campbell KW (1997) Empirical near-source attenuation relationships for horizontal and vertical components of peak ground acceleration, peak ground velocity, and pseudo-absolute acceleration response spectra. Seismol Res Lett 68:154-179

Draper NR, Smith H (1981) Applied Regression Analysis, 2nd edn. Wiley, New York, p 709

El-Hadidy S (2015) Seismicity and seismotectonic setting of the Red Sea and adjacent areas. In: Rasual NMA, Stewart ICF (eds) The Red Sea: the formation, morphology, oceanography and environment of a young ocean basin. Springer, London, pp 151-159

Fukushima Y, Tanaka T (1990) A new attenuation relation for peak horizontal acceleration of strong earthquake ground motion in Japan. Bull Seismol Soc Am 80:757-783

Gupta A, Baker JW, Ellsworth WL (2017) Assessing ground motion amplitudes and attenuation for small-to-moderate induced and tectonic earthquakes in the Central and Eastern United States. Seismol Res Lett 88:1379-1389

Joyner WB, Boore DM (1981) Peak horizontal acceleration and velocity from strong-motion records including records from the 1979 Imperial Valley, California, earthquake. Bull Seismol Soc Am 71: 2011-2038
Joyner WB, Boore DM (1993) Methods for regression analysis of strongmotiondata. Bull Seism Soc Am 83(2):469-487

Kiuchi R, Mooney WD, Zahran HM (2019)Ground-motion prediction equations for Western Saudi Arabia. Bull Seismol Soc Am. https:// doi.org/10.1785/012018030

Lanczos C (1961) Linear Differential Operators. D. Van Nostrand, New Jersey 564 pp

Pankow KL, Pechmann JC (2004) The SEA99 ground-motion predictive relations for extensional tectonic regimes: revisions and a new peak ground velocity relation. Bull Seismol Soc Am 94:341-348

Pasyanos ME, Walter WR, Matzel EM (2009) A simultaneous multiphase approach to determine $\mathrm{P}$-wave and S-wave attenuation of the crust and upper mantle. Bull Seismol Soc Am 99:3314-3325

Press WH, Teukolsky SA, Vetterling WT, Flannery BP (1992)Numerical Recipes in FORTRAN, The Art of Scientific Computing, 2nd edn. Cambridge U Press, New York $968 \mathrm{pp}$

Rodgers A, Walter W, Mellors R, Al-Amri A, Zhang Y (1999) Lithospheric structure of the Arabian shield and platform from complete regional waveform modelling and surface wave group velocities. Geophys J Int 138:871-878

Sadigh K, Chang C-Y, Egan JA, Makdisi F, Youngs RR (1997) Attenuation relationships for shallow crustal earthquakes based on California strong motion data. Seismol Res Lett 68:180-189

Skarlatoudis A, Theodulidis N, Papaioannou C, Roumelioti Z (2004) The dependence of peak horizontal acceleration on magnitude and distance for small magnitude earthquakes in Greece. $13^{\text {th }}$ World Conference on Earthquake Engineering, Vancouver, British Columbia, Canada, August 1-6, 2004; Paper No. 1857, p 12 pp

Thenhaus PC, Algermissen ST, Perkins DM, Hanson SL, Diment WH (1989) Probabilistic estimates of the seismic ground-motion hazard in western Saudi Arabia. USGS Bull 1868:40pp

Wu YM, Shin TC, Chang CH (2001) Near real-time mapping of peak ground acceleration and peak ground velocity following a strong earthquake. Bulletin of the Seismological Society of America 91(5):1218-1228

Zhao JX, Zhang J, Asano A, Ohno Y, Oouchi T, Takahashi T, Ogawa H, Irikura K, Thio HK, Somerville PG et al (2006) Attenuation relations of strong ground motion in Japan using site classification based on predominant period. Bull Seismol Soc Am 96:898-913

Zahran HM, Sokolov V, El-Hadidy S, Alradadi WW (2015) Preliminary probabilistic seismic hazard assessment for the Kingdom of Saudi Arabia based on combined areal source model: Monte Carlo approach and sensitivity analyses. Soil Dyn Earthq Eng 77:453-468. https://doi.org/10.1016/j.soildyn.2015.06.011

Zahran HM, Sokolov V, Roobol MJ, Stewart ICF, El-Hadidy SY, ElHadidy M (2016) On the development of a seismic source zonation model for seismic hazard assessment in western Saudi Arabia. J Seismol 20(3):747-769. https://doi.org/10.1007/s10950-016-9555-y 